\title{
Oral Health and Risk Indicators of Early Adolescents in Shandong Province, China: A Cross-sectional Oral Health Survey
}

\author{
Meng Zhang \\ Shandong University \\ Jing Lan \\ Shandong University \\ Tiantian Zhang \\ Shandong University \\ Wenshuang Sun \\ Shandong University \\ Panpan Liu \\ Shandong University \\ Zhifeng Wang ( $\square$ kqwzf@sdu.edu.cn ) \\ Shandong University
}

\section{Research Article}

Keywords: Dental caries, Gingivitis, Adolescents, Oral health, Risk indicators

Posted Date: January 18th, 2021

DOI: https://doi.org/10.21203/rs.3.rs-145470/v1

License: (c) (i) This work is licensed under a Creative Commons Attribution 4.0 International License. Read Full License 


\section{Abstract}

Objective: We aimed to analyse the oral health status of adolescents in Shandong province, including dental caries and gingivitis, and the relevant risk indicators.

Methods: Adolescents aged 12-15-years in Shandong province were recruited. Caries and gingival status were assessed following the World Health Organisation diagnostic criteria. Information including the sociodemographic, oral hygiene knowledge, attitudes and practices were collected through the questionnaire. Chi-square test and multivariate logistic regression analysis were used to investigate the independent risk indicators.

Results: In total, 3,868 students (50.2\% males) were enrolled. Of these, $39.9 \%$ of the participants experienced caries, and $81.7 \%$ and $31.3 \%$ had calculus and bleeding gums, respectively. Multivariate logistic regression analysis revealed that there was an association between an increased risk of caries with toothaches, dental visits and sleeping troubles caused by oral problems $(P<0.024)$. A low-frequency of brushing, high sugar consumption and no flossing increased the risk of calculus formation and gum bleeding $(P<0.008)$.

Conclusion: Compared to caries, worse gingival condition was more prevalent among adolescents in Shandong province and was not taken seriously. Brushing behaviour is associated with gingivitis, while dental visits and toothaches are associated with caries. Hence, preventionoriented dental visits and oral hygiene training are strongly recommended to improve oral health status.

Trial registration: Not applicable.

\section{Introduction}

Dental caries is among the most prevalent oral disease worldwide and are a significant economic burden[1, 2]. Early stage of permanent dentition occurs between the ages of 12 to 15 years, with oral health being critical for this age group. In addition, it is important to instil good oral hygiene behaviour and lifestyle habits during this period[3]. Hence, understanding and controlling the risk factors of oral diseases during this period helps to better maintain oral health.

Compared to early childhood caries, limited data are available on the assessment of oral health status in the early stage of permanent dentition. The oral habits and ideology that adolescents form is related to oral health status[4,5]. Poor oral health can result not only in dental caries but also obvious gingival inflammation[6]. At this time, if the related risk factors are not evaluated, and the intervention measures are not implemented in time to correct poor habits[7, 8], these irreversible oral problems will affect the life of the teeth and even the person's general quality of life[9-11]. Hence, the association of age, sex, region, socioeconomic conditions, personal and professional dental care, and dental anxiety with dental caries, gingivitis and oral health-related quality of life in adolescents have been evaluated and evidenced by some crosssectional studies[9, 10,12,13]. However, regional-based inequalities mean that the risk factors associated with oral diseases can differ, even among indigenous and nonindigenous children and adolescents[14]. Therefore, to provide targeted, specific, and efficient oral health care to the population, regional-based related risk factors should be explored.

As a representative province in East China, Shandong province has special dietary habits. This study aimed (1) to describe the status of dental caries and gingivitis in 12-15-year-old adolescents in Shandong province and (2) to identify the relevant risk indicators to provide reference for the improvement of oral health education.

\section{Methods}

This cross-sectional study uses a part of the 4th National Oral Health Survey conducted in China. All parents gave their informed consent for inclusion before their children participated in the study. The study was conducted in accordance with the Declaration of Helsinki, and the protocol was approved by the Ethics Committee of the Chinese Stomatological Association (NO. 2014-003).

The sample size was calculated based on the data of the 3rd National Oral Health Survey in 2005, in which the prevalence of dental caries for those aged 12 years was $28.9 \%$. The design effect (deff $=4.5)$, significance level $(a=5 \%)$, margin of error $(\delta=10 \%)$ and non-response rate $(20 \%)$ were also included in the following formula:

$$
n=\operatorname{deff} \frac{u_{\alpha} / 2^{2}}{\delta^{2}} p(1-p)
$$

In total, 28,365 12-15-year-old adolescents should be recruited in 31 provinces across the country[15]. Hence, at least 3,660 individuals should be enrolled in this study. A multistage cluster sampling method was adopted to select the sample population. The probability proportion to size 
sampling determined that two urban and two rural samples should be used. Cluster and quota sampling determined the three primary high schools in each region. Three hundred and twenty students (80 for each age group) from each school were included.

After giving their informed consent, the students completed the questionnaire survey and underwent an oral examination. The questionnaire collected information on the students' personal and family demographics, including age, gender, region, father/mother's education level, whether they were an only child or had siblings, and the following:

1) Oral hygiene knowledge, including the impact of brushing, bacteria, sugar, fluoride, pit and fissure sealing, and other factors that affect the teeth and gingiva.

2) Oral hygiene attitude, mainly to evaluate whether they believe that oral health is important.

3) Oral hygiene behaviours, including brushing habits, frequency of snacking, smoking, dentist visits, and trauma.

4) Troubles caused by oral problems, including eating, talking, brushing, working, schooling, sleeping, smiling, easily troubled, and communicating.

All clinical examinations were implemented at schools with external equipment (portable dental chair, disposable dental mirror, ball-ended community periodontal index probe, and intraoral light-emitting diode light). Three examiners were selected and trained. The clinical practice training would be terminated when the Kappa value was greater than 0.8 to ensure the consistency of the inter- and intra-examiners. The following indices were used according to the criteria recommended by the World Health Organisation[16]. The DMFT, calculus (CI) and gingival bleeding (GB) indexes assessed decay, missing teeth caused by decay, filled teeth and the gingival health status. All teeth present were gently probed with a CPI probe at six sites, including mesial, mid, and distal on both buccal and lingual surfaces. Calculus and gingival bleeding were scored as present (1) or absent (0) and the number of teeth where calculus/bleeding was present were recorded.

Data were entered and statistically analysed using IBM SPSS Statistics version 21.0. The prevalence and average of dental caries (DMFT, DT, MT, FT), calculus and gingival bleeding were calculated. Since the measured count data were not normally distributed, their prevalence was used to assess the association of these indices and other variables. The indicators were all binary variables, and the other independent variables were also categorical. All the variables were independent of each other. Hence, Chi-square, Fisher's exact and $z$ tests for post hoc comparisons were conducted to explore the relationship between these oral indicators and the sociodemographic and questionnaire variables. To evaluate the independent risk factors associated with caries and gingivitis in adolescents, a multivariate logistic regression model (method: backward logistic regression) was used. Those variables with $P \leq 0.10$ obtained through bivariate analyses were examined if they should be included in the final models. The tolerance and variance inflation factors obtained through the linear regression model were used to diagnose multicollinearity between independent variables. A $P$-value of $<0.05$ was considered statistically significant.

\section{Results}

A total of 3,868 students aged $12-15$ years were enrolled. The mean age of the participants was $13.95 \pm 1.11$ and $50.2 \%$ were males. As shown in Table 1, 39.9\% of participants experienced dental caries ( $87.7 \%$ DT, $0.8 \% \mathrm{MT}, 21.5 \% \mathrm{FT}$ ), and $81.7 \%$ and $31.3 \%$ of participants had calculus and bleeding gums, respectively. The mean (SD) DT, FT, DMFT, Cl, and GB were $0.68 \pm 1.22,0.18 \pm 0.77,0.86 \pm 1.47,5.61 \pm 4.91$, and $1.58 \pm$ 3.58 , respectively (data not shown). 
Table 1

Statistical significance by demographic variables for DMFT, Cl and GB among 12-15-year-old students $(n=3868)$. N (\%)

\begin{tabular}{|c|c|c|c|c|c|c|c|c|c|}
\hline \multirow[t]{2}{*}{ Variables } & \multicolumn{3}{|l|}{ Caries } & \multicolumn{3}{|l|}{ Calculus } & \multicolumn{3}{|c|}{ Gingival bleeding } \\
\hline & Absence & Presence & $P$-value & Absence & Presence & $P$-value & Absence & Presence & $P$-value \\
\hline Total & $2326(60.1 \%)$ & 1542(39.9\%) & & 708(18.3\%) & $3160(81.7 \%)$ & & $2656(68.7 \%)$ & $1212(31.3 \%)$ & \\
\hline \multicolumn{10}{|l|}{ Age group } \\
\hline $12 y$ & $\begin{array}{l}589(62.7 \%) \\
a\end{array}$ & $\begin{array}{l}351(37.3 \%) \\
a\end{array}$ & 0.041 & $\begin{array}{l}225(23.9 \%) \\
\mathrm{a}\end{array}$ & $\begin{array}{l}715(76.1 \%) \\
a\end{array}$ & $<0.001$ & $\begin{array}{l}666(70.9 \%) \\
a\end{array}$ & $\begin{array}{l}274(29.1 \%) \\
a\end{array}$ & 0.01 \\
\hline $13 y$ & $\begin{array}{l}582(59.2 \%) \\
a, b\end{array}$ & $\begin{array}{l}401(40.8 \%) \\
a, b\end{array}$ & & $\begin{array}{l}175(17.8 \%) \\
\text { b }\end{array}$ & $\begin{array}{l}808(82.2 \%) \\
b\end{array}$ & & $\begin{array}{l}666(67.8 \%) \\
a, b\end{array}$ & $\begin{array}{l}317(32.2 \%) \\
a, b\end{array}$ & \\
\hline $14 y$ & $\begin{array}{l}597(61.9 \%) \\
\mathrm{a}\end{array}$ & $\begin{array}{l}368(38.1 \%) \\
\mathrm{a}\end{array}$ & & $\begin{array}{l}178(18.4 \%) \\
\text { b }\end{array}$ & $\begin{array}{l}787(81.6 \%) \\
\mathrm{b}\end{array}$ & & $\begin{array}{l}687(71.2 \%) \\
\mathrm{a}\end{array}$ & $\begin{array}{l}278(28.8 \%) \\
a\end{array}$ & \\
\hline $15 y$ & $\begin{array}{l}558(56.9 \%) \\
b\end{array}$ & $\begin{array}{l}422(43.1 \%) \\
\mathrm{b}\end{array}$ & & $\begin{array}{l}\text { 130(13.3\%) } \\
\mathrm{C}\end{array}$ & $\begin{array}{l}850(86.7 \%) \\
\mathrm{C}\end{array}$ & & $\begin{array}{l}637(65.0 \%) \\
\text { b }\end{array}$ & $\begin{array}{l}343(35.0 \%) \\
b\end{array}$ & \\
\hline \multicolumn{10}{|l|}{ Gender } \\
\hline Male & $\begin{array}{l}1300(66.9 \%) \\
\mathrm{a}\end{array}$ & $\begin{array}{l}642(33.1 \%) \\
\mathrm{a}\end{array}$ & $<0.001$ & $\begin{array}{l}281(14.5 \%) \\
a\end{array}$ & $\begin{array}{l}1661(85.5 \%) \\
\mathrm{a}\end{array}$ & $<0.001$ & $1313(67.6 \%)$ & $629(32.4 \%)$ & 0.155 \\
\hline Female & $\begin{array}{l}1026(53.3 \%) \\
b\end{array}$ & $\begin{array}{l}900(46.7 \%) \\
\mathrm{b}\end{array}$ & & $\begin{array}{l}427(22.2 \%) \\
b\end{array}$ & $\begin{array}{l}1499(77.8 \%) \\
\text { b }\end{array}$ & & $1343(69.7 \%)$ & $583(30.3 \%)$ & \\
\hline \multicolumn{10}{|c|}{ Urban and rural } \\
\hline Urban & $1145(59.2 \%)$ & $790(40.8 \%)$ & 0.222 & $\begin{array}{l}380(19.6 \%) \\
a\end{array}$ & $\begin{array}{l}1555(80.4 \%) \\
a\end{array}$ & 0.032 & $\begin{array}{l}1270(65.6 \%) \\
a\end{array}$ & $\begin{array}{l}665(34.4 \%) \\
a\end{array}$ & $<0.001$ \\
\hline Rural & $1181(61.1 \%)$ & $752(38.9 \%)$ & & $\begin{array}{l}328(17.0 \%) \\
b\end{array}$ & $\begin{array}{l}1605(83.0 \%) \\
b\end{array}$ & & $\begin{array}{l}1386(71.7 \%) \\
b\end{array}$ & $\begin{array}{l}547(28.3 \%) \\
b\end{array}$ & \\
\hline \multicolumn{10}{|l|}{ Region } \\
\hline $\begin{array}{l}\text { Shouguang } \\
\text { Weifang }\end{array}$ & $\begin{array}{l}540(56.4 \%) \\
\text { a }\end{array}$ & $\begin{array}{l}418(43.6 \%) \\
\mathrm{a}\end{array}$ & $<0.001$ & $\begin{array}{l}187(19.5 \%) \\
\mathrm{a}\end{array}$ & $\begin{array}{l}771(80.5 \%) \\
a\end{array}$ & 0.001 & $\begin{array}{l}665(69.4 \%) \\
a\end{array}$ & $\begin{array}{l}293(30.6 \%) \\
a\end{array}$ & $<0.001$ \\
\hline $\begin{array}{l}\text { Huancui, } \\
\text { Weihai }\end{array}$ & $\begin{array}{l}550(58.0 \%) \\
a\end{array}$ & $\begin{array}{l}399(42.0 \%) \\
\mathrm{a}\end{array}$ & & $\begin{array}{l}168(17.7 \%) \\
\mathrm{a}\end{array}$ & $\begin{array}{l}781(82.3 \%) \\
\mathrm{a}\end{array}$ & & $\begin{array}{l}588(62.0 \%) \\
b\end{array}$ & $\begin{array}{l}361(38.0 \%) \\
b\end{array}$ & \\
\hline $\begin{array}{l}\text { Hedong, } \\
\text { Linyi }\end{array}$ & $\begin{array}{l}595(60.3 \%) \\
a, b\end{array}$ & $\begin{array}{l}391(39.7 \%) \\
a, b\end{array}$ & & $\begin{array}{l}212(21.5 \%) \\
b\end{array}$ & $\begin{array}{l}774(78.5 \%) \\
\text { b }\end{array}$ & & $\begin{array}{l}682(69.2 \%) \\
\mathrm{a}\end{array}$ & $\begin{array}{l}304(30.8 \%) \\
\mathrm{a}\end{array}$ & \\
\hline $\begin{array}{l}\text { Pingyi, } \\
\text { Linyi }\end{array}$ & $\begin{array}{l}641(65.7 \%) \\
b\end{array}$ & $\begin{array}{l}334(34.3 \%) \\
b\end{array}$ & & $\begin{array}{l}141(14.5 \%) \\
\mathrm{C}\end{array}$ & $\begin{array}{l}834(85.5 \%) \\
\mathrm{C}\end{array}$ & & $\begin{array}{l}721(73.9 \%) \\
\mathrm{C}\end{array}$ & $\begin{array}{l}254(26.1 \%) \\
\mathrm{C}\end{array}$ & \\
\hline \multicolumn{10}{|c|}{ An only child or not? } \\
\hline Yes & $\begin{array}{l}913(62.7 \%) \\
\mathrm{a}\end{array}$ & $\begin{array}{l}542(37.3 \%) \\
\mathrm{a}\end{array}$ & 0.01 & $274(18.8 \%)$ & $1181(81.2 \%)$ & 0.51 & $997(68.5 \%)$ & $458(31.5 \%)$ & 0.881 \\
\hline No & $\begin{array}{l}1413(58.6 \%) \\
b\end{array}$ & $\begin{array}{l}1000(41.4 \%) \\
b\end{array}$ & & $434(18.0 \%)$ & $1979(82.0 \%)$ & & $1659(68.8 \%)$ & $754(31.2 \%)$ & \\
\hline \multicolumn{10}{|c|}{ Father's education level } \\
\hline $\begin{array}{l}\text { Never go to } \\
\text { school }\end{array}$ & $10(62.5 \%)$ & $6(37.5 \%)$ & 0.286 & $3(18.8 \%)$ & $13(81.3 \%)$ & 0.712 & $9(56.3 \%)$ & $7(43.8 \%)$ & 0.274 \\
\hline $\begin{array}{l}\text { Elementary } \\
\text { or junior } \\
\text { high school }\end{array}$ & $1476(61.3 \%)$ & $932(38.7 \%)$ & & $425(17.6 \%)$ & 1983(82.4\%) & & $1646(68.4 \%)$ & $762(31.6 \%)$ & \\
\hline $\begin{array}{l}\text { High } \\
\text { school }\end{array}$ & $318(56.6 \%)$ & $244(43.4 \%)$ & & $112(19.9 \%)$ & $450(80.1 \%)$ & & $374(66.5 \%)$ & 188(33.5\%) & \\
\hline $\begin{array}{l}\text { College or } \\
\text { university }\end{array}$ & $349(59.9 \%)$ & $234(40.1 \%)$ & & $109(18.7 \%)$ & $474(81.3 \%)$ & & $418(71.7 \%)$ & $165(28.3 \%)$ & \\
\hline
\end{tabular}

a, b, c: Differences between the row variables, the same mark represents no difference between the two variables. 


\begin{tabular}{|c|c|c|c|c|c|c|c|c|c|}
\hline \multirow[t]{2}{*}{ Variables } & \multicolumn{3}{|l|}{ Caries } & \multicolumn{3}{|l|}{ Calculus } & \multicolumn{3}{|c|}{ Gingival bleeding } \\
\hline & Absence & Presence & $P$-value & Absence & Presence & $P$-value & Absence & Presence & $P$-value \\
\hline $\begin{array}{l}\text { No father } \\
\text { or do not } \\
\text { know }\end{array}$ & $173(57.9 \%)$ & $126(42.1 \%)$ & & $59(19.7 \%)$ & $240(80.3 \%)$ & & $209(69.9 \%)$ & $90(30.1 \%)$ & \\
\hline \multicolumn{10}{|c|}{ Mother's education level } \\
\hline $\begin{array}{l}\text { Never go to } \\
\text { school }\end{array}$ & $\begin{array}{l}103(68.7 \%) \\
a\end{array}$ & $47(31.3 \%) \mathrm{a}$ & 0.005 & $29(19.3 \%)$ & $121(80.7 \%)$ & 0.519 & $103(68.7 \%)$ & $47(31.3 \%)$ & 0.255 \\
\hline $\begin{array}{l}\text { Elementary } \\
\text { or junior } \\
\text { high school }\end{array}$ & $\begin{array}{l}1545(61.2 \%) \\
\text { b }\end{array}$ & $\begin{array}{l}978(38.8 \%) \\
\mathrm{b}\end{array}$ & & $446(17.7 \%)$ & $2077(82.3 \%)$ & & $1728(68.5 \%)$ & $795(31.5 \%)$ & \\
\hline $\begin{array}{l}\text { High } \\
\text { school }\end{array}$ & $197(53 \%) \mathrm{c}$ & $175(47 \%) \mathrm{c}$ & & $74(19.9 \%)$ & $298(80.1 \%)$ & & $247(66.4 \%)$ & $125(33.6 \%)$ & \\
\hline $\begin{array}{l}\text { College or } \\
\text { university }\end{array}$ & $\begin{array}{l}290(59.1 \%) \\
\mathrm{C}\end{array}$ & $\begin{array}{l}201(40.9 \%) \\
C\end{array}$ & & $101(20.6 \%)$ & $390(79.4 \%)$ & & $357(72.7 \%)$ & $134(27.3 \%)$ & \\
\hline $\begin{array}{l}\text { No mother } \\
\text { or do not } \\
\text { know }\end{array}$ & $\begin{array}{l}191(57.5 \%) \\
b, c\end{array}$ & $\begin{array}{l}141(42.5 \%) \\
b, c\end{array}$ & & $58(17.5 \%)$ & $274(82.5 \%)$ & & $221(66.6 \%)$ & $111(33.4 \%)$ & \\
\hline
\end{tabular}

Table 1 summarises the sociodemographic variables associated with DMFT, Cl, and GB. As for DMFT, the prevalence of dental caries increased with age $(P=0.041)$. Females were more likely to experience caries than males $(P<0.001)$. Pingyi in Linyi had a statistically lower prevalence of caries than other regions $(P<0.001)$. Besides, adolescents without siblings and those whose mother had lower education levels were less likely to develop caries $(P=0.01$ and 0.005$)$. Moreover, no statistical difference was found between urban and rural regions and among father's education levels. As for dental calculus, age and the calculus detection rates also showed a positive correlation $(P<0.001)$. Boys $(P<0.001)$ and rural areas, including Pingyi (Linyi) and Shouguang (Weifang), generally had a higher prevalence than urban areas $(P=0.032$ and 0.001$)$, while the prevalence rates between those with and without siblings and among father's/mother's education levels were not statistically significant. As for $\mathrm{GB}$, the 15-year-old group had the highest prevalence $(P=0.01)$. Furthermore, the prevalence of students living in an urban area, such as Huancui (Weihai), was higher $(P<0.001)$. However, gender, whether they had siblings and parents' education levels, did not correlate with GB.

The independent behavioural variables with significant differences associated with DMFT, Cl and GB, are summarised in Supplementary Table S1-3. A high prevalence of DMFT was correlated with the following variables: teeth brushing habits and brushing over two times per day (Q4 and Q5), higher frequency of sugar consumption (Q9), poorer self-evaluation of oral condition (Q12), toothaches and dentist visits (Q15-18; $P<$ 0.05). Furthermore, those students who did not believe that regular oral examinations are necessary (Q20b) and who thought that caries had a negative impact on eating, schooling, sleeping and easily troubled (Q21) had a higher prevalence of dental caries $(P<0.05)$. Those with a higher frequency of brushing (Q5), higher sugar consumption (Q9a), dental visits (Q16), and believed that regular oral examinations are necessary (Q20b) were associated with a lower prevalence of dental calculus $(P<0.05)$. In addition, a high prevalence of $\mathrm{GB}$ was associated with a lower frequency of brushing and flossing (Q5 and Q8), poorer self-evaluation of oral condition (Q12), and the belief that gum bleeding is normal when brushing (Q19a; $P<0.05)$.

The multivariate logistic regression analysis revealed that adolescents who were older, female, living in an urban environment, had siblings, a poorer self-evaluation of oral condition, experienced toothaches, visited a dentist, and had sleeping disturbance caused by oral problems had a statistically higher prevalence of DMFT (Table 2). Interestingly, no brushing and sugar consumption variables were included in the final DMFT model. In the $\mathrm{Cl}$ model (Table 3), there was a higher prevalence of dental calculus in those that were older, male, living in Huancui and Pingyi, and did not visit a dentist. Besides, a low-frequency of brushing (1/day: OR: $1.421,95 \% \mathrm{Cl}: 1.158-1.742, P=0.001 ;<1 /$ day: OR: $1.691,95 \% \mathrm{Cl}$ : 1.209-2.364, $P=0.002$ ) and sugar consumption (OR: $1.75,95 \% \mathrm{Cl}: 1.161-2.639, P=0.008)$ were also found to contribute to a higher prevalence of calculus. The GB model (Table 4) revealed that the students who brushed their teeth less than twice a day (1/day: OR: $1.235,95 \% \mathrm{Cl}: 1.028-$ 1.483, $P=0.024 ;<1 /$ day: OR: $1.791,95 \% \mathrm{Cl}: 1.373-2.335, P<0.001$ ) and do not use dental floss (OR: $1.928,95 \% \mathrm{Cl}: 1.373-2.706, P<0.001)$ generally experienced worse gum bleeding. Moreover, age, living region, and the belief that gum bleeding when brushing is normal were also associated with GB. 
Table 2

Multivariable logistic regression model for dental caries $(n=$ 3868; method: backward).

\begin{tabular}{|c|c|c|c|}
\hline Variables & OR & $95 \% \mathrm{Cl}$ & $P$-value \\
\hline \multicolumn{4}{|l|}{ Age group } \\
\hline $12 y$ & 1 & NA & NA \\
\hline $13 y$ & 1.176 & $0.971-1.425$ & 0.096 \\
\hline $14 y$ & 1.045 & $0.861-1.268$ & 0.653 \\
\hline $15 y$ & 1.322 & $1.092-1.601$ & 0.004 \\
\hline \multicolumn{4}{|l|}{ Region } \\
\hline Shouguang, Weifang & 1.397 & $1.140-1.711$ & 0.001 \\
\hline Huancui, Weihai & 1.435 & $1.158-1.779$ & 0.001 \\
\hline Hedong, Linyi & 1.12 & $0.923-1.360$ & 0.252 \\
\hline Pingyi, Linyi & 1 & NA & NA \\
\hline \multicolumn{4}{|l|}{ Gender } \\
\hline Female & 1.69 & $1.471-1.943$ & $<0.001$ \\
\hline Male & 1 & NA & NA \\
\hline \multicolumn{4}{|l|}{ An only child or not? } \\
\hline Yes & 1 & NA & NA \\
\hline$M=N o$ & 1.253 & $1.065-1.474$ & 0.007 \\
\hline \multicolumn{4}{|c|}{ Q12 self-evaluation of oral health condition } \\
\hline great & 1 & NA & NA \\
\hline good & 1.415 & $1.0-2.003$ & 0.05 \\
\hline general & 1.518 & $1.080-2.134$ & 0.016 \\
\hline poor & 2.633 & $1.82-3.896$ & $<0.001$ \\
\hline severe & 3.346 & $1.783-6.278$ & $<0.001$ \\
\hline \multicolumn{4}{|c|}{ Q15 toothache in the past 12 months } \\
\hline Usually & 2.207 & $1.391-3.501$ & 0.001 \\
\hline Occasionally & 1.482 & $1.264-1.736$ & $<0.001$ \\
\hline Do not remember & 0.995 & $0.795-1.244$ & 0.963 \\
\hline Never & 1 & NA & NA \\
\hline \multicolumn{4}{|l|}{ Q16 visited a dentist } \\
\hline Yes & 1.728 & $1.501-1.990$ & $<0.001$ \\
\hline Never & 1 & NA & NA \\
\hline \multicolumn{4}{|c|}{ Q21f the impact of oral problems on sleeping } \\
\hline Serious impact & 1.538 & $1.080-2.190$ & 0.017 \\
\hline General impact & 0.998 & $0.749-1.330$ & 0.991 \\
\hline Minor impact & 1.193 & $0.980-1.452$ & 0.079 \\
\hline Unclear & 0.756 & $0.527-1.084$ & 0.128 \\
\hline No impact & 1 & NA & NA \\
\hline
\end{tabular}

Page 6/12 
Table 3

Multivariate logistic regression model for calculus (method: backward).

\begin{tabular}{|c|c|c|c|}
\hline variables & OR & $95 \% \mathrm{Cl}$ & $P$-value \\
\hline \multicolumn{4}{|l|}{ Age group } \\
\hline $12 y$ & 1 & NA & NA \\
\hline $13 y$ & 1.566 & $1.227-2$ & $<0.001$ \\
\hline $14 y$ & 1.366 & $1.074-1.736$ & 0.011 \\
\hline $15 y$ & 2.131 & $1.65-2.753$ & $<0.001$ \\
\hline \multicolumn{4}{|l|}{ Region } \\
\hline Shouguang, Weifang & 1.236 & $0.972-1.573$ & 0.084 \\
\hline Huancui, Weihai & 1.456 & $1.133-1.871$ & 0.003 \\
\hline Pingyi, Linyi & 1.554 & $1.190-2.028$ & 0.001 \\
\hline Hedong, Linyi & 1 & NA & NA \\
\hline \multicolumn{4}{|l|}{ Gender } \\
\hline Male & 1.57 & $1.307-1.886$ & $<0.001$ \\
\hline Female & 1 & NA & NA \\
\hline \multicolumn{4}{|c|}{ Q5 frequency of brushing $(n=3356)$} \\
\hline$\geq 2 /$ day & 1 & NA & NA \\
\hline $1 /$ day & 1.421 & $1.158-1.742$ & 0.001 \\
\hline$<1 /$ day & 1.691 & $1.209-2.364$ & 0.002 \\
\hline \multicolumn{4}{|c|}{ Q9a frequency of having sweets } \\
\hline Seldom or never & 1.75 & $1.161-2.639$ & 0.008 \\
\hline $1-3 /$ month & 1.37 & $0.944-1.988$ & 0.098 \\
\hline 1/week & 1.318 & $0.951-1.827$ & 0.097 \\
\hline $2-6 /$ week & 1.311 & $0.981-1.752$ & 0.067 \\
\hline 1/day & 1.1 & $0.8-1.512$ & 0.557 \\
\hline$\geq 2 /$ day & 1 & NA & NA \\
\hline \multicolumn{4}{|c|}{ Q16 whether visited a dentist } \\
\hline Yes & 1 & NA & NA \\
\hline Never & 1.249 & $1.037-1.504$ & 0.019 \\
\hline
\end{tabular}


Table 4

Multivariate logistic regression model for gingival bleeding (method: backward)

\begin{tabular}{|c|c|c|c|}
\hline variables & OR & $95 \% \mathrm{Cl}$ & $P$-value \\
\hline \multicolumn{4}{|l|}{ Age group } \\
\hline $12 y$ & 1.09 & $0.876-1.356$ & 0.441 \\
\hline $13 y$ & 1.27 & $1.027-1.571$ & 0.028 \\
\hline $14 y$ & 1 & NA & NA \\
\hline $15 y$ & 1.354 & $1.1-1.667$ & 0.004 \\
\hline \multicolumn{4}{|l|}{ Region } \\
\hline Shouguang, Weifang & 1.288 & $1.032-1.608$ & 0.025 \\
\hline Huancui, Weihai & 2.109 & $1.686-2.636$ & $<0.001$ \\
\hline Hedong, Linyi & 1.233 & $0.989-1.537$ & 0.063 \\
\hline Pingyi, Linyi & 1 & NA & NA \\
\hline \multicolumn{4}{|c|}{ Q5 frequency of brushing $(n=3356)$} \\
\hline$\geq 2 /$ day & 1 & NA & NA \\
\hline $1 /$ day & 1.235 & $1.028-1.483$ & 0.024 \\
\hline$<1 /$ day & 1.791 & $1.373-2.335$ & $<0.001$ \\
\hline \multicolumn{4}{|c|}{ Q8 frequency of using dental floss } \\
\hline Never & 1.928 & $1.373-2.706$ & $<0.001$ \\
\hline Occasionally & 1 & NA & NA \\
\hline Weekly use & 0.642 & $0.135-3.061$ & 0.579 \\
\hline Daily use & 1.24 & $0.311-4.954$ & 0.76 \\
\hline \multicolumn{4}{|c|}{ Q19a is gum bleeding normal when brushing your teeth? } \\
\hline Yes & 1.516 & $1.225-1.875$ & $<0.001$ \\
\hline Do not know & 1.322 & $1.025-1.704$ & 0.031 \\
\hline No & 1 & NA & NA \\
\hline
\end{tabular}

\section{Discussion}

Shandong province, as one of the birthplaces of the ancient Chinese civilisation, has nearly 100 million inhabitants. The province has progressed in industry and agriculture, and have developed special eating habits (the major staple food is flour). However, few studies have reported the oral health status of residents living in Shandong. This study evaluated the sociodemographic, clinical, oral health knowledge, attitudes, and behavioural factors among 12-15-year-old students in Shandong province and explored the different roles of non-clinical variables on the DMFT, $\mathrm{Cl}$, and GB indices (clinical variables). The results show that the prevalence of caries in Shandong province is similar to the national level (31.9\% vs $41.9 \%$ )[17], but the detection rate of calculus is significantly higher than it is nationally (81.7\% vs $67.3 \%$ ). Contrastingly, the gingival bleeding rate is significantly lower than nationally (31.3\% vs $61.0 \%)[18]$. Therefore, the relevant risk factors need to be analysed so that tailored and effective guidance can be provided to enable adolescent oral health in Shandong province to be improved.

Dental caries are an age-related disease[19-21], and are due to the continuous development of oral diseases over time without any intervention[22]. Here, we found that females generally experienced worse caries than males. Some studies have speculated that this is because girls prefer sugar, have hormonal fluctuations in puberty and menstruation[23], or due to sex-based diverse plaque microbiome[24]. However, the caries risk due to gender is not consistent between studies[25, 26], which might be because of the different samples and regions used. Boys tend to have more severe gingival health status than girls, as supported by many studies[27-29]. This may be due to girls having better oral 
hygiene habits[4]. Risk factors, such as age, gender, and region are all uncontrollable, even if there are significant differences. Therefore, stratification is important for the analysis and assessment of the risk factors at different levels. Moreover, an analysis of controllable risk variables is more important to provide robust guidance for oral health education content.

The contribution of toothbrushing to remove dental plaque and maintain oral health has been proven[30-32]. However, many of these crosssectional studies and even longitudinal studies[13,14,33] are consistent with our results and do not provide sufficient evidence for the positive effect of toothbrushing on caries prevention. This may be due to better living standards, and better access to knowledge and information regarding brushing and appropriate frequency of brushing. Furthermore, the use of fluoride toothpaste has increased. Nevertheless, it is still unclear as to whether the toothbrushing practices get the maximum effect to remove dental plaque[8]. As such, a correlation between brushing, frequency of brushing, fluoride toothpaste and dental caries has not been evidenced. In contrast, an increasing number of prospective intervention studies have confirmed that additional brushing guidance or even just a simple application of plaque disclosing tables can improve oral hygiene[34,35]. Hence, an assessment of brushing efficiency should be incorporated into future research to estimate the correlation between toothbrushing and dental caries more accurately. In addition, the positive effect of brushing more than twice a day on calculus formation and gum bleeding were confirmed in our study. Evidence shows that, without considering the efficacy of tooth brushing, correct oral hygiene can help to maintain gum health $[4,36]$.

Preventative dental visits are highly recommended[37]. However, in China, there seems to be still a long way to go, as dental visits were generally associated with worse caries status[38,39], and dental visits for treatment is a vital attribution factor. Better calculus status was detected among adolescents who had visited the dentist (Supplementary Table S2, Table 3), which may be related to the time-efficiency of calculus removal. Furthermore, those individuals that had experienced a toothache in the past 12 months, and sleeping troubles caused by oral problems were found to have a more severe caries status (Supplementary Table S1, Table 2), so they evaluated themselves as having poor oral health. However, $81.7 \%$ of individuals with calculus and $31.3 \%$ with gum bleeding, did not realize that their oral health was very poor. Furthermore, $14.1 \%$ of adolescents thought that gum bleeding was normal when brushing teeth, indicating that compared to caries, some characteristics of gingivitis, especially the formation of calculus, are not often taken seriously or even ignored when adolescents self-evaluate oral health status. If adolescents continue to pay little attention to initial periodontal inflammation, more serious periodontal issues will inevitably appear in the future[6]. Therefore, these aspects should be focussed on when conducting oral health education in the future.

The sufficient sample size and the comprehensive collection of various potential risk factor information enabled this study to reliably evaluate the oral health status of adolescents in Shandong province. However, the present study also had some limitations. First, cross-sectional studies are unable to prove causal inference. Second, the correlation between toothbrushing and caries could not be accurately evaluated because toothbrushing efficiency was not assessed. Third, even though the region that the adolescents lived in was a risk factor that correlated with DMFT, Cl, and GB, no information on the familial socioeconomic status was recorded. It is known that familial socioeconomic status is closely linked with oral health status[40-42]. Due to living standard improvements, a simple urban-rural classification does not truly reflect the correlation between socioeconomic status and oral health.

\section{Conclusion}

In conclusion, compared to caries, worse gingival condition is more prevalent among adolescents in Shandong and its signs are not taken seriously. Age, gender, region, toothaches, dental visits and sleeping troubles caused by oral problems were found to contribute to a higher risk of dental caries in adolescents. A low-frequency of brushing and sugar consumption was associated with the formation of calculus. A lowfrequency of brushing and no flossing was found to increase the risk of gum bleeding. Preventative dental visits and oral hygiene training are strongly recommended to improve oral health status.

\section{Abbreviations}

DMFT: decayed, missing and filled permanent teeth; Cl: calculus index; GB: gingival bleeding index; OR: odd rates; Cl: confidence interval.

\section{Declarations}

\section{Ethics approval and consent to participate:}

The experimental protocol was established, according to the ethical guidelines of the Helsinki Declaration and was approved by the Ethics Committee of the Chinese Stomatological Association (N0.2014-003). Written informed consent was obtained from adolescent's legal caregivers.

\section{Consent for publication:}


Not applicable.

\section{Availability of data and materials:}

The datasets used and analyzed during the current study are available from the corresponding author on reasonable request.

\section{Competing interests:}

The authors declare that they have no competing interests.

\section{Funding:}

All phases of this study were supported by the Chinese Stomatological Association and School \& Hospital of Stomatology, Shandong University. The design of this study and collection, analysis, and interpretation of data and the manuscript writing are funded by the Key Technology Research and Development Program of Shandong Province (grant number: 2019GSF108278 and 2019GSF108184), National Natural Science Foundation of China (grant number: 81671025), and the Department of Science and Technology of Shandong Province (grant number: ZR2018ZB0105).

\section{Authors' contributions:}

ZF W conceptualized and designed the study, ZF W and J L reviewed and revised the manuscript. M Z organized data, carried out the statistical analyses, drafted and revised the manuscript. TT Z and WS S collected, input and organized data. PP L instructed the methods and strategies of statistical analyses. All authors reviewed the manuscript. All authors read and approved the final manuscript.

\section{Acknowledgements:}

Our warmest thanks to the Chinese Stomatological Association for providing the raw survey data. Thank you also for the cooperation and assistance of the various primary and high schools.

\section{References}

1. MA Peres, LMD Macpherson, RJ Weyant, B Daly, R Venturelli, MR Mathur, S Listl, RK Celeste, CC Guarnizo-Herreño, C Kearns, H Benzian, P Allison, RG Watt. Oral diseases: a global public health challenge. Lancet. 2019; 394(10194):249-60.

2. Kassebaum NJ Smith AGC, Bernabé E, Fleming TD, Reynolds AE, Vos T, Murray CJL, Marcenes W, and GBD 2015 Oral Health Collaborators. Global, regional, and national incidence, prevalence, and years lived with disability for 328 diseases and injuries for 195 countries, 1990 2016: a systematic analysis for the Global Burden of Disease Study 2016. Lancet. 2017; 390(10100):1211-59.

3. AJ Al-Hussyeen. Factors affecting utilization of dental health services and satisfaction among adolescent females in Riyadh City. The Saudi dental journal. 2010; 22(1):19-25.

4. JP Woelber, H Bienas, G Fabry, W Silbernagel, M Giesler, C Tennert, S Stampf, P Ratka-Krüger, E Hellwig. Oral hygiene-related self-efficacy as a predictor of oral hygiene behaviour: a prospective cohort study. Journal of clinical periodontology. 2015; 42(2):142-9.

5. CBDF Cumerlato, FF Demarco, AJD Barros, MA Peres, KG Peres, A Morales Cascaes, MBJ de Camargo, I da Silva Dos Santos, A Matijasevich, MB Corrêa. Reasons for direct restoration failure from childhood to adolescence: A birth cohort study. J Dent. 2019; 89:103183.

6. BK Drummond, MG Brosnan, JW Leichter. Management of periodontal health in children: pediatric dentistry and periodontology interface. Periodontology. 2017; 74(1):158-67.

7. G Thornton-Evans, ML Junger, M Lin, L Wei, L Espinoza, E Beltran-Aguilar. Use of Toothpaste and Toothbrushing Patterns Among Children and Adolescents - United States, 2013-2016. Morbidity mortality weekly report. 2019; 68(4):87-90.

8. S Jepsen, J Blanco, W Buchalla, JC Carvalho, T Dietrich, C Dörfer, KA Eaton, E Figuero, JE Frencken, F Graziani, SM Higham, T Kocher, M Maltz, A Ortiz-Vigon, J Schmoeckel, A Sculean, LM Tenuta, MH van der Veen, V Machiulskiene. Prevention and control of dental caries and periodontal diseases at individual and population level: consensus report of group 3 of joint EFP/ORCA workshop on the boundaries between caries and periodontal diseases. Journal of clinical periodontology. 2017; doi:10.1111/jcpe.12687:S85-S93. 
9. B Xiang, HM Wong, AP Perfecto, CPJ McGrath. The association of socio-economic status, dental anxiety, and behavioral and clinical variables with adolescents' oral health-related quality of life. Quality of life research. 2020; doi:10.1007/s11136-020-02504-7.

10. SA Eid, NMA Khattab, AAH Elheeny. Untreated dental caries prevalence and impact on the quality of life among 11 to14-year-old Egyptian schoolchildren: a cross-sectional study. BMC Oral Health. 2020; 20(1):83.

11. GF Ferrazzano, C Salerno, G Sangianantoni, S Caruso, A Ingenito, T Cantile. The Effect of Dental Treatment under General Anesthesia on Quality of Life and Growth and Blood Chemistry Parameters in Uncooperative Pediatric Patients with Compromised Oral Health: A Pilot Study. International journal of environmental research public health. 2020; 17(12).

12. ZC Kyaw Myint, T Zaitsu, A Oshiro, M Ueno, KK Soe, Y Kawaguchi. Risk indicators of dental caries and gingivitis among 10-11-year-old students in Yangon, Myanmar. Int Dent J. 2020; 70(3):167-75.

13. A Du, H Zhang, C Chen, F Zhang, X Liu, Z Zhang, R Wang. Oral health of 12-year-old children in Jilin province, China: A population-based epidemiological survey. Medicine. 2019; 98(51):e18463.

14. X Ju, L Do, D Ha, L Jamieson. Association of Modifiable Risk Factors With Dental Caries Among Indigenous and Nonindigenous Children in Australia. JAMA network open. 2019; 2(5):e193466.

15. HX Lu, DY Tao, ECM Lo, R Li, X Wang, BJ Tai, Y Hu, HC Lin, B Wang, Y Si, CX Wang, SG Zheng, XN Liu, WS Rong, WJ Wang, XP Feng. The 4th National Oral Health Survey in the Mainland of China: Background and Methodology. The Chinese journal of dental research. 2018; 21(3):161-5.

16. (WHO) World Health Organization. Oral health surveys: basic methods. 5th edition: Gevena: World Health Organization; 2013.

17. JK Quan, XZ Wang, XY Sun, C Yuan, XN Liu, X Wang, XP Feng, BJ Tai, Y Hu, HC Lin, B Wang, Y Si, CX Wang, WJ Wang, WS Rong, SG Zheng. Permanent Teeth Caries Status of 12- to 15-year-olds in China: Findings from the 4th National Oral Health Survey. The Chinese journal of dental research. 2018; 21(3):181-93.

18. X Chen, W Ye, JY Zhan, X Wang, BJ Tai, Y Hu, HC Lin, B Wang, Y Si, CX Wang, SG Zheng, XN Liu, WS Rong, WJ Wang, XP Feng. Periodontal Status of Chinese Adolescents: Findings from the 4th National Oral Health Survey. The Chinese journal of dental research. 2018; 21(3):195203.

19. K Montanha-Andrade, W Maia, ACP Pimentel, YBOL Arsati, JND Santos, PR Cury. Dental health status and its indicators in adult Brazilian Indians without exposition to drinking water fluoridation: a cross-sectional study. Environmental science pollution research international. 2019; 26(33):34440-7.

20. H lida, P Auinger, RJ Billings, M Weitzman. Association between infant breastfeeding and early childhood caries in the United States. Pediatrics. 2007; 120(4):e944-52.

21. E Bernabé, A Sheiham. Age, period and cohort trends in caries of permanent teeth in four developed countries. American journal of public health. 2014; 104(7):e115-21.

22. Pitts Nigel B., Zero Domenick T., Marsh Phil D., Ekstrand Kim, Weintraub Jane A., Ramos-Gomez Francisco, Tagami Junji, Twetman Svante, Tsakos Georgios, Ismail Amid. Dental caries. Nature Reviews Disease Primers. 2017; 3(1):17030.

23. JR Lukacs, LL Largaespada. Explaining sex differences in dental caries prevalence: saliva, hormones, and "life-history" etiologies. American journal of human biology. 2006; 18(4):540-55.

24. de Jesus VC, Shikder R, Oryniak D, Mann K, Alamri A, Mittermuller B, Duan K, Hu P, Schroth RJ, Chelikani P. Sex-Based Diverse Plaque Microbiota in Children with Severe Caries. J Dent Res. 2020; 99(6):703-12.

25. E Mamai-Homata, H Koletsi-Kounari, V Margaritis. Gender differences in oral health status and behavior of Greek dental students: A metaanalysis of 1981, 2000, and 2010 data. Journal of International Society of Preventive Community Dentistry. 2016; 6(1):60-8.

26. K Wang, L Pang, Y Tao, X Li, J Zhang, T Cui, B Zeng, H Lin. Association of genetic and environmental factors with dental caries among adolescents in south China: A cross-sectional study. European journal of paediatric dentistry. 2020; 21(2):129-36.

27. AML Pedersen, M Darwish, J Nicholson, MI Edwards, AK Gupta, D Belstrøm. Gingival health status in individuals using different types of toothpaste. J Dent. 2019; doi:10.1016/j.jdent.2018.08.008:S13-S8.

28. LB Christensen, PE Petersen, M Steding-Jessen. Consumption of dental services among adults in Denmark 1994-2003. European journal of oral sciences. 2007; 115(3):174-9.

29. HJ Shiau, MA Reynolds. Sex differences in destructive periodontal disease: a systematic review. Journal of periodontology. 2010; 81(10):1379-89.

30. HW Scherp. Dental caries: prospects for prevention. Science. 1971; 173(4003):1199-205.

31. HV Worthington, L MacDonald, T Poklepovic Pericic, D Sambunjak, TM Johnson, P Imai, JE Clarkson. Home use of interdental cleaning devices, in addition to toothbrushing, for preventing and controlling periodontal diseases and dental caries. Cochrane Database Syst Rev. 2019; 4:CD012018. 
32. T Walsh, HV Worthington, AM Glenny, VC Marinho, A Jeroncic. Fluoride toothpastes of different concentrations for preventing dental caries. Cochrane Database Syst Rev. 2019; 3:CD007868.

33. S Suzuki, Y Onose, K Yoshino, A Takayanagi, H Kamijo, N Sugihara. Factors associated with development of root caries in dentition without root caries experience in a 2-year cohort study in Japan. J Dent. 2020; 95:103304.

34. KA Gray-Burrows, PF Day, Z Marshman, E Aliakbari, SL Prady, RR McEachan. Using intervention mapping to develop a home-based parental-supervised toothbrushing intervention for young children. Implementation science. 2016; 11:61.

35. Y Shiotsu-Ogura, A Yoshida, P Kan, H Sasaki, T Toyama, K Izukuri, N Hamada, F Yoshino. Antimicrobial photodynamic therapy using a plaque disclosing solution on Streptococcus mutans. Photodiagnosis photodynamic therapy. 2019; 26:252-7.

36. S Mizutani, D Ekuni, M Furuta, T Tomofuji, K Irie, T Azuma, A Kojima, J Nagase, Y Iwasaki, M Morita. Effects of self-efficacy on oral health behaviours and gingival health in university students aged 18- or 19-years-old. Journal of clinical periodontology. 2012; 39(9):844-9.

37. CC Guarnizo-Herreño, GL Wehby. Dentist supply and children's oral health in the United States. American journal of public health. 2014; 104(10):e51-7.

38. N Obregón-Rodríguez, P Fernández-Riveiro, M Piñeiro-Lamas, E Smyth-Chamosa, A Montes-Martínez, MM Suárez-Cunqueiro. Prevalence and caries-related risk factors in schoolchildren of 12- and 15-year-old: a cross-sectional study. BMC Oral Health. 2019; 19(1):120.

39. M Zhang, X Zhang, Y Zhang, Y Li, C Shao, S Xiong, J Lan, Z Wang. Assessment of risk factors for early childhood caries at different ages in Shandong, China and reflections on oral health education: a cross-sectional study. BMC Oral Health. 2020; $20(1): 139$.

40. Petersen P. E., Bourgeois D., Ogawa H., Estupinan-Day S., Ndiaye C. The global burden of oral diseases and risks to oral health. Bull World Health Organ. 2005; 83(9):661-9.

41. AR Hosseinpoor, L Itani, PE Petersen. Socio-economic inequality in oral healthcare coverage: results from the World Health Survey. J Dent Res. 2012; 91(3):275-81.

42. AL Östberg, M Petzold. A longitudinal study of the impact of change in socioeconomic status on dental caries in the permanent dentition of Swedish children and adolescents. Community dentistry oral epidemiology. 2020; doi:10.1111/cdoe.12529.

\section{Supplementary Files}

This is a list of supplementary files associated with this preprint. Click to download.

- Supplementaryfile.docx 